MEMÓRIA

\title{
CODETEC - Companhia de Desenvolvimento Tecnológico
}

\author{
Rogério Cezar de Cerqueira Leite \\ Professor Emérito da UNICAMP
}

A concepção da CODETEC nasceu de um paradoxo fértil como costuma acontecer com inovações. À época era tradicional na universidade brasileira a repulsa ao uso de meios pertencentes a universidades para atividades pré-empresariais. Enquanto em muitas das universidades americanas era comum a tolerância quanto ao uso de espaço, equipamentos, intelectos e mesmo mão-de-obra técnica para atividades precursoras à implantação de indústrias. Uma maneira de contornar esse conflito foi oficializá-lo.

Os exemplos flagrantes, extremamente construtivos observados em universidades americanas de onde surgiam importantes empreendimentos de conseqüências econômicas marcantes, consentiam na aceitação de riscos inerentes a atividades estranhas à tradição universitária corrente. Foi com essa consciente certeza de conflito de interesse que foi concebida a CODETEC.

Para tornar operacional e estruturada conceitualmente a CODETEC, foi convidado o professor Aldo Vieira da Rosa, cuja experiência anterior no Brasil e no exterior se encaixava com perfeição no perfil necessário para tal empreendimento. O professor Aldo Vieira da Rosa havia sido um dos fundadores do complexo ITA (Instituto Tecnológico de Aeronáutica) - CTA (Centro Técnico Aeroespacial), tendo criado o INPE (Instituto Nacional de Pesquisas Espaciais) e o IPD (Instituto de Pesquisa e Desenvolvimento) do CTA. 
O professor Aldo Vieira da Rosa havia iniciado sua vida profissional como militar, tendo-se aposentado como brigadeiro-do-ar. Posteriormente à sua estadia no Brasil para criação da CODETEC, retornou à Stanford, tornando-se, posteriormente, professor emérito dessa universidade. No texto abaixo, o professor Aldo Vieira da Rosa expõe com clareza as suas idéias sobre a CODETEC.

A CODETEC nasceu, em 1976, de uma reunião na Universidade de Campinas, patrocinada pelo Ministério de Indústria e Comércio. A reunião, convocada pelo professor Rogério Cesar Cerqueira Leite, se propunha a identificar meios de agilizar a criação de novos empreendimentos tecnológicos no setor privado, reconhecendo ser esse o principal mecanismo que leva à independência tecnológica de um país.

Da reunião, surgiu uma comissão que redigiu um documento sugerindo a formação de uma companhia privada, com fortes ligações com a UNICAMP, dedicada a facilitar o estabelecimento por parte de professores e alunos da Universidade de pequenas empresas capazes de gerar tecnologia apropriada para as condições brasileiras.

Surgiu assim a CODETEC, tendo como presidente de seu conselho o professor Cerqueira Leite. As ações foram subscritas por várias indústrias brasileiras de grande porte. A primeira tarefa foi a de analisar os obstáculos que dificultam no Brasil o florescimento de pequenas empresas tecnológicas, uma situação que contrasta com o vigor dessas atividades em países como a Alemanha e os Estados Unidos.

Em nossa terra, várias circunstâncias militavam contra a transformação do professor ou aluno universitário em pequeno empresário. A mais óbvia era o princípio da dedicação exclusiva, criado para evitar que professores fizessem do ensino nada mais que um bico. Outro empecilho à movimentação do pessoal universitário para o mundo empresarial era o custo do insucesso.

O estabelecimento de uma empresa traz consigo apreciável probabilidade de insucesso capaz de consumir todos fundos investidos e de invalidar os esforços e trabalhos expendidos. O custo de tal insucesso desencoraja o futuro empreendedor. Por outro lado, uma agência que cria não uma mas numerosas empresas tem a segurança estatística de que uma certa porcentagem de tais empresas vai suceder. 
O modus operandi da CODETEC era o de acolher professores e alunos munidos de boas idéias cobrindo as despesas do período de desenvolvimento e implantação comercial, oferecendo instalaçôes e laboratórios apropriados para a execução do projeto proposto. Caso o projeto não demonstrasse viabilidade comercial, ele era considerado um simples estudo do qual ensinamentos eram colhidos. Caso a viabilidade comercial fosse confirmada, o projeto era destacado da CODETEC, e uma empresa independente era formada. A CODETEC tinha opção de vir a ser acionista e, em alguns casos, de cobrar royalties. Professores e alunos trabalhavam durante o período probatório em instalações dentro da própria UNICAMP, e o seu trabalho era reconhecido como pesquisa de valor acadêmico, não constituindo uma infração do princípio de dedicação exclusiva.

Para ter sucesso, tempo e fundos suficientes seriam necessários. Infelizmente, os fundos levantados foram patentemente inadequados. Conseqüentemente, embora vários problemas tenham sido atacados com grande entusiasmo e alguns terem resultado em empreendimentos independentes, a companhia foi definhando e abandonou os seus planos iniciais para se adaptar a atividades outras.

De início é bom notar que houve duas fases bem distintas da CODETEC. Durante a primeira fase funcionou como uma incubadora de empresas e foi possivelmente a primeira incubadora do mundo, se descartarmos a atuação informal de universidades, principalmente nos EUA na geração de empresas de tecnologia. Foram gestadas na CODETEC empresas de várias origens e em vários campos de atividades. Dentre as mais destacadas, foram a CRIOMETAL, que se ocupava da produção de equipamentos criogênicos e que foi absorvida posteriormente pelo grupo MANGELS. A TERMOQUIP, empresa que atuava na área de produção de energia a partir da biomassa por intermédio de tecnologias de gaseificação e que absorveu parte da diretoria da própria CODETEC ao ser formada, permitindo saudável renovação do corpo técnico da CODETEC.

Uma série de outras empresas, cerca de dez, foram criadas na área de aproveitamento de energia solar. Outra empresa que alcançou dimensões elevadas foi a NOVADATA, que iniciou suas atividades produzindo minicomputadores. Outra empresa que teve uma certa consequiência comercial 
foi a UNILASER, a primeira empresa nacional a produzir lasers. Através de um contrato com a CESP, a CODETEC passou a produzir hidrolisadores e instalá-los em indústrias químicas, o que permitia que estas comprassem hidrogênio e não eletricidade.

Para demonstrar a versatilidade do trabalho feito pela CODETEC em sua primeira fase, mencionaremos dois contratos firmados com a Cooperativa do Trigo de Ijuí (COTRIJUÍ). No primeiro desses contratos, foram projetados e implantados sistemas de previsão de safras e de preços. Os equipamentos foram instalados e um pessoal local de Porto Alegre foi treinado pela CODETEC. Esses dois sistemas foram possivelmente os primeiros instalados no Brasil com tecnologia de ponta.

O segundo contrato com a COTRIJUí se referiu ao planejamento de um processo de colonização na Amazônia e envolveu mais que uma centena de pesquisadores. Não somente foram feitas medidas sobre fertilidade de solo, variedades de vegetais passíveis de uma silvicultura sustentável, como arquitetura e distribuição de terras adequadas para o meio ambiente. Foram treinados monitores para adequar os colonos provenientes do Rio Grande do Sul ao novo habitat. Apesar do sucesso do projeto e de sua plena aceitação, não foi possível a implantação devido à hostilidade de poderosos "grileiros".

Como já mencionado no texto do professor Aldo Vieira da Rosa, após essa primeira fase, a CODETEC definhou. A principal razão para essa mudança foi a saída do professor Zeferino Vaz da Reitoria e conseqüentemente a supressão do apoio que a Universidade dava à CODETEC. Apoio este que não se restringia ao fornecimento de espaço físico e mão-de-obra, como também se estendia à própria aceitação da CODETEC como extensão natural da missão universitária.

Uma segunda fase da CODETEC se iniciou timidamente devido a uma oportunidade casual. José Carlos Gerez é o principal ator desse renascimento da CODETEC. Quando estudante de engenharia na Faculdade de Engenharia Industrial, foi acusado de subversão, tendo sido preso pelo DOPS, passando por várias prisões, incluindo-se o Carandiru. Colocado em liberdade condicional em 1965, fugiu para o Uruguai, tendo de lá obtido uma bolsa de estudos para estudar no Instituto Superior de Tecnologia Química de Sofia, Bulgária. Lá, conseguiu um fato inédito, tendo sido primeiro aluno 
em todas as disciplinas e em todos os anos. Regressou em 1975 para o Brasil, indo trabalhar em vários laboratórios de empresas multinacionais. Em 1984, aceitou a insólita posição de vice-diretor da combalida CODETEC.

Dentre os primeiros projetos da CODETEC em sua segunda fase, já em prédio próprio, construído dentro de terreno da UNICAMP, foi desenvolvida uma tecnologia de produção de etanol a partir do bagaço de cana por hidrólise ácida. Essa tecnologia foi desenvolvida para as Indústrias Villares, por contrato. $\mathrm{O}$ sucesso da planta-piloto de hidrólise ácida motivou a COPERSUCAR a contratar a CODETEC para a produção de equipamentos de hidrólise por explosão a vapor (Steam Explosion). Esses equipamentos foram instalados em várias usinas com a finalidade de melhor aproveitamento do bagaço como alimento para gado.

A grande ascensão da CODETEC veio com a inauguração de um novo modelo para indústria de química fina no Brasil. O ministro Hélio Beltrão, do Ministério da Previdência Social no início da administração Figueiredo, aceitou a formulação de uma política agressiva e inovadora para o setor farmacêutico. Os financiamentos seriam feitos para indústrias brasileiras de porte intermediário, que usariam tais recursos exclusivamente para financiar o desenvolvimento de processos de produção de fármacos na CODETEC. Em compensação, a indústria farmacêutica que assumia a responsabilidade do empréstimo tinha direitos ao mercado intermediado pela Central de Medicamentos. Àquela época a farmácia básica nacional era composta por aproximadamente 350 fármacos essenciais. Outro fator importante para o sucesso dessa política era o fato de que a farmácia brasileira à época era composta em $95 \%$ dos seus itens por fármacos com proteção intelectual expirada. O entendimento entre a CODETEC e o Ministério de Previdência Social, ao qual estava então vinculada a Central de Medicamentos, era de que a CODETEC se dedicaria ao desenvolvimento, através de engenharia reversa, de processos de produção de fármacos.

Foram então construídas as plantas-piloto integradas de grande versatilidade e os laboratórios de apoio. A CODETEC chegou a empregar cerca de 300 funcionários e desenvolveu 80 processos, dos quais cerca de 20 chegaram a ser comercializados por diferentes empresas nacionais. A CODETEC acompanhou e eventualmente concebeu e construiu várias plantas 
para o setor produtivo, em várias companhias brasileiras do setor de química fina. Algumas companhias foram criadas com tecnologia desenvolvida pela CODETEC.

$\mathrm{O}$ mercado de produtos farmacêuticos no Brasil, à época, era inteiramente dominado por empresas multinacionais. Sobreviviam apenas algumas pequenas empresas de capital brasileiro que atuavam na marginalidade do mercado. Nenhum fármaco era produzido no Brasil e tanto as multinacionais quanto as brasileiras eram obrigadas a importar seus insumos. Sem capacidade de produção de fármacos, não era possível sequer avaliar custos de produção. Os preços eram, portanto, determinados pelo jogo dos oligopólios estrangeiros.

Duas ações de natureza informativa e política foram tomadas com apoio na CODETEC. Um levantamento na CACEX, entidade ligada ao Banco do Brasil, hoje extinta, era responsável por importação e exportação de toda e qualquer espécie. Foram obtidos dados sigilosos da CACEX e detectado um fenômeno bastante estranho: insumos eram importados por um preço e por vezes reexportado por preços muito inferiores, por vezes dez vezes menores. Parecia óbvio que importação e exportação de fármacos estavam sendo usados para envio de divisas, sem pagamento dos respectivos impostos.

Defesas pífias tanto da CACEX como das multinacionais foram facilmente desqualificadas. A presidência da CACEX foi mudada e, pelo menos por algum tempo, ficaram as multinacionais sem esses meios de enviar divisas ilegalmente. Também foi feita uma campanha para a implantação do sistema de genéricos no país, obviamente encontrando ferrenha oposição das empresas multinacionais do setor.

Como indício de que essas ações e o próprio trabalho já iniciado pela CODETEC incomodavam muita gente, a CODETEC recebeu a visita do cônsul-geral dos EUA, acompanhado de técnicos. Nenhum dos planos da CODETEC foi ocultado. A CODETEC também encontrou resistências em setores governamentais, pois a compra de remédio pelo governo era uma tradicional forma de corrupção. Isso não se restringia ao governo federal, mas se estendia também aos estados e municípios.

De fato, o primeiro golpe fatal contra a CODETEC foi dado ainda no governo Collor, quando o então secretário-geral do Ministério da Saúde, 
Luiz Romero Farias (irmão de P. C. Farias), interrompeu todos os contratos com as empresas que se valiam da CODETEC. Durante a administração Itamar Franco, houve um pequeno ressurgimento da CODETEC, mas não foi suficiente para impedir que no próximo governo, o de Fernando Henrique Cardoso, a situação se tornasse tão crítica que ela tivesse sido obrigada a ser vendida.

Não foram apenas as circunstâncias externas que terminaram com a instituição. Houve também uma questão estrutural, pois, com a missão específica e altamente especializante de elaboração de processos de produção de fármacos, perdeu-se a diversificação e conseqüentemente a adaptabilidade, um fenômeno bem conhecido da biologia evolutiva. Apenas alguns projetos foram realizados que não se referiam à produção de fármacos; dentre eles o desenvolvimento de um composto antidetonante para adição ao álcool, com a finalidade de adaptá-lo a motores diesel e o desenvolvimento de combustíveis sólidos para foguetes. O primeiro projeto foi feito para a Indústrias Químicas de Taubaté, e o segundo, para o Ministério da Aeronáutica.

Outro fator determinante para o ocaso da CODETEC foi o falecimento prematuro de seu principal executivo, José Carlos Gerez. Um projeto alternativo que permitiria a sobrevivência da CODETEC durante o governo Fernando Henrique Cardoso, adverso a qualquer projeto de independência nacional em relação a insumos essenciais provenientes do exterior, estava em gestação na CODETEC. Tratava-se da produção de pequenos volumes de fármacos especiais para o mercado interno. Entretanto, sem o seu principal idealizador, o projeto não pode ter continuidade.

A natureza adota duas estratégias básicas para a sobrevivência de espécies. Uma se baseia na especialização extrema, o que confere enorme eficiência. A segunda se vale de um aprofundamento de sua adaptabilidade, o que permite a adequação a mudanças de ambiente. A CODETEC adotou a primeira e por isso sucumbiu. É um exemplo para empresas brasileiras que habitam um ambiente em permanente transição. 